\title{
Aviadores en el desierto. Aventura y viaje del capitán Rafael Martínez Esteve en el Hamad jordano-iraquí (1926)
}

Joaquín $M^{a}$ Córdoba

Arbor CLXXX, 711-712 (Marzo-Abril 2005), 913-936 pp.

$A$ comienzos del siglo $X X$, cuando el redescubrimiento de Oriente se había trocado en su colonización tras la I Guerra Mundial, la poesía del viaje y el reencuentro con gentes y paisajes parecian ya imposibles. De hecho, la literatura "clásica" del viaje a Oriente estaba ya más que acabada. Sin embargo, un accidente de la historia de la aviación española haría que el capitán Rafael Martínez Esteve, integrante de la patrulla que emprendió el viaje Madrid-Manila, viviera una trágica aventura en el desierto jordano-iraquí. Fruto de esa experiencia sería un libro que es, al mismo tiempo que emocionante relato, descripción poética del desierto y la vida de los beduinos, sarcástica mirada a los poderes coloniales, y un amable epigono en la historia de la literatura española de viajes a Oriente.

A la memoria de mi hermano Rafael, que no pudo colmar su anhelo de ser aviador.

Por el vuelo eterno que si emprendió.

Llanura desértica inmensa, infinita, desasosegante en su aplastante quietud, pedregosa a veces, desnuda casi de arbusto alguno, ilimitada bajo un cielo que se va hundiendo en la noche. Es el enorme al-Hamad, 
la planicie que se extiende al norte del arábigo y arenoso Nafud, entre la Cisjordania y el remoto valle del Eufrates iraquí. Silencio absoluto, como sólo lo hay en los mayores desiertos de la tierra. Y éste lo es. Una figura se recorta en el horizonte, andando a trompicones, con evidentes muestras de agotamiento. Se deja caer. No lleva nada consigo. Viste un uniforme militar de color verdoso y apenas reconocible, lleno de polvo, desgarrado, con la guerrera abierta. Musitando algo se acurruca sobre su costado izquierdo, buscando descanso para un cuerpo dolorido. La respiración es un gemido arrancado a una garganta reseca. De su boca llagada y de sus labios cortados salen semipalabras, estertores, sonidos desarticulados. Acaso sueña. Y se arrebuja en su guerrera. Crece el frío de la noche del desierto. Descalzo, sus pies parecen dos muñones oscuros y deformes. Embarrados, ensangrentados, resecos, llenos de espinas incrustadas. Gime y sueña, agotado. Es un aviador perdido en el desierto.

La noche se llena de ruidos, gañidos lejanos, aullidos, ladridos. Bajo las estrellas, una vida inesperada empieza a rebullir marcando sus senderos. Una bandada de ojos felinos se topa en su rápida marcha con la figura acurrucada. Siguen su rastro hace tiempo. Le rodean, se tumban a cierta distancia, le observan, le huelen, le sienten. Son hienas. Y esperan bajo el frío. Esperan. Como más tarde escribirá en sus recuerdos "al despertar, cubierto de frío sudor, ahuyento a una manada de hienas que han velado mi sueño; huyen asustadas, rasgando el silencio de la noche serena con sus siniestros aullidos» ${ }^{1}$. Enfebrecido, ve llegar el amanecer y continúa su marcha. Pasan las horas y camina, dando traspiés, pero camina. Sin detenerse. Su mente traza planes de salvación, pues se cree cercano a los pozos de Imiri y a los campamentos beduinos. Sus labios intentan repetir en árabe las palabras con las que espera saludarles. Casi sueña en realidad, mientras camina, camina, camina, pero ya va atardeciendo otra vez, y recuerda estremecido los ojos brillantes de las hienas que sin duda, más allá del horizonte le ventean. De pronto, en lo alto suenan motores de aviones. Agotado, casi indiferente, apenas si levanta los ojos. Son dos biplanos británicos De Havilland, de patrulla rumbo a Amman. No le verán, seguro. Han pasado tantos ya sin verle, ... Mas incompresiblemente, un tripulante asoma la cabeza esta vez. Le ha visto. Está a menos de cien metros de altura y le hace señas con los brazos. Poco después, tras un aterrizaje en la llanura, un joven teniente inglés llamado Coggle corre presuroso hacia el atormentado caminante. $\mathrm{Y}$ se presentan, ceremoniosos, firmes, estrechándose la mano. El capitán Rafael Martínez Esteve, náufrago en el desierto de la patrulla española en ruta hacia Manila, ha sido salva- 
do. Así lo contará después. Y así ocurrió sufriendo, viviendo y renaciendo de una aventura en el desierto.

\section{De aviadores, aterrizajes forzosos, desiertos y libros}

Ocurrió todo aquello un mes de abril del año 1926, cuando la aviación naciente vivía aún su época gloriosa de retos y aventuras, cuando los que estaban a los mandos sentían el aire en el rostro y volaban pendientes del relieve geográfico visible allá abajo, que tantas veces les marcaba la distancia entre la vida y la muerte. Cuando las grandes tormentas invernales o las de sofocantes arenas se llevaban a tantos. Ocurrió entonces, cuando los que volaban eran más que pilotos, verdaderos aviadores.

Pasada la I Guerra Mundial y convertidos en mito los primeros héroes del aire, como Manfred von Richthofen, Max Immelmann o Georges Guynemenr y sus frágiles aviones Fokker y Spad, la tercera década del siglo sería la época de los grandes vuelos. Los portugueses S. Cabral y G. Coutinho la abrieron en 1922, volando de Lisboa a Río de Janeiro por etapas en un hidro. Y el comandante italiano De Pinedo, que en 1925 cubrió las 30.000 millas entre Italia y Australia, retornando vía Japón. Pero la historia que me interesa ahora no es ésta, sino la de otros tres pioneros, que además de coetáneos y cruzarse en sus vidas sin saberlo, sufrieron aterrizajes forzosos en la nada, sobrevivieron apenas en la inmensidad del desierto y publicaron libros que testimonian, pese a todo, que lo amaron y lo entendieron. Ellos son Rafael Martínez Esteve, László E. Almásy y Antoine de Saint-Exupéry. Ellos son, o así me lo parece a mí, los «aviadores del desierto".

Si los primeros aviones hubieran dejado estelas permanentes en los cielos, veríamos que los vuelos de un español nacido en Valencia en $1894^{2}$, un austro-húngaro venido al mundo en Bernstein en $1895^{3}$, y un francés que nació en Lyon en $1900^{4}$ cruzaron sus rumbos sobre los desiertos, en los cielos inmensos que se extienden desde Cabo Juby hasta el Mar de Arena libio y el valle del Nilo. Los tres nacieron en una familia acomodada, los tres amaron volar y los tres vivieron y vieron en el desierto cosas que marcarían sus vidas. $Y$ los tres escribieron sus recuerdos, aunque el tono y carácter de sus páginas difiera notablemente. Y aunque sólo uno fuera capaz de encontrarse con le petit prince en la soledad de las noches estrelladas, dunas inmensas y planicies interminables, los otros dos sufrieron también muchas de las situaciones de ensueño y espejismos de las que nació el joven príncipe. El mayor de los tres 
fue el español, formado como aviador en Zaragoza y Alcalá de Henares, piloto de guerra en Marruecos, que en 1923 aterrizó en Cabo Juby, organizando el primer enlace militar aéreo con aquel puesto español de la costa del Sáhara, donde había de vivir después Antoine de Saint Exupéry ${ }^{5}$. Volando hacia Manila, en 1926 divisó a su derecha el Gran Mar de Arena y los oasis sobre los que cinco años después se elevaría Almásy, y los arenales donde tendría que aterrizar en tantas ocasiones. Luego vendría la etapa hacia Bagdad, y su aterrizaje en el desolado desierto de al-Hamad al encuentro de su leyenda y su destino. Ya en España publicó un relato extraño, Una aventura en el desierto (Madrid, 1926), libro de viaje y aventura, que nos ha conservado su emotivo encuentro con Oriente y sus beduinos, entre magníficos paisajes, agonías angustiosas y una buena cantidad de curiosas escenas. Y después, la carrera y la nada. Pero de eso hablaremos más adelante.

Los mismos cielos por los que voló Esteve los cruzó László Ede Almásy ${ }^{6}$, nacido en la antigua Hungría occidental, el Burgenland actual, de padre húngaro y madre austriaca. Desde la adolescencia amó los automóviles y los aeroplanos, y con diecisiete años obtuvo su licencia de vuelo. Consumado políglota, durante la I Guerra Mundial combatió en la aviación, y luego realizó las actividades más diversas, desde conductor de pruebas en una fábrica de coches a representante de la misma firma en Egipto, o guía de safaris y viajes aristocráticos hasta el corazón africano. Viviendo en el país del Nilo unió su amor por el desierto y su pasión por el vuelo, organizando exploraciones combinadas a la búsqueda de los secretos del Gran Mar de Arena. Como en los casos de Esteve o SaintExupéry, su árabe fluido le permitió comprenderse con las gentes y acercarse a su propia visión del mundo, a su mentalidad, tanto que los beduinos le llamaron $A b u$ Ramla, y le estimaban mucho porque "también tú conoces el desierto". Con su avioneta «Polilla» y sus vehículos, apoyado por mecenas como Sir Robert Clayton, divisó por vez primera el uadi Abd al Malik y el legendario oasis de Zarzura; no lejos de allí encontró la más que célebre Cueva de los nadadores, y en los montes Arkanu centenares de pinturas rupestres. Volar por el desierto era peligroso, pues la única forma de orientarse todavía era la observación visual por el piloto de una línea, unas rodadas, una pista, costa, río o uadi, lo mismo que habían hecho Esteve o Saint-Exupéry. Y Almásy volaba sobre el desierto, perdía el rumbo con las tormentas de arena y lo reencontraba, siempre al borde del abismo. Con él, sus aventuras y su leyenda se pergeñó muchos años después el guión de una película que le ha hecho ahora célebre, El paciente inglés, de Anthony Minghella (1977), aunque la romantización del héroe 
y su apasionado amor por la esposa de Sir Robert Clayton sean una completa, aunque carnal y emotiva invención. En 1934 publicó en Hungría El Sáhara desconocido, relatando sus hallazgos y aventuras por tierra y aire en los desiertos que tanto amaba. Tras participar en la II Guerra Mundial y su posterior cautiverio, consiguió pasaporte austriaco y vivió en Viena y Roma. Pero la llamada del desierto le devolvió a El Cairo. En 1949, quiso retomar con un planeador la búsqueda del ejército de Cambises, pero no encontró el apoyo necesario. Enfermo de una amebiasis no curada, volvió a Europa y murió en Salzburgo en marzo de 1951, siete años después que Saint-Exupéry y catorce antes que Martínez Esteve.

Más prolífico en sus relatos, incomparablemente más célebre y creador de mitos culturales de nuestro tiempo sería Antoine de SaintExupéry ${ }^{7}$, que a los doce años se enamoró de los aviones y del vuelo cuando un feliz verano de los pasados en el chateau de Saint-Maurice, propiedad de la tía de su madre, descubrió el campo de aviación de Ambérieu, donde se fabricaban y probaban los primeros aeroplanos. Con su hermana Gabrielle se metía entre obreros y mecánicos, preguntando y descubriendo cosas maravillosas, hasta que a fines de julio de $1912 \mathrm{Ga}$ briel Wroblewski se lo llevó con él en un corto vuelo que siempre recordaría deslumbrado. Adolescente en París, tras su fallido intento de ingresar en la Escuela Naval, se decidió por la de Bellas Artes, y en el hôtel de su prima Yvonne de Lestrange conoció a Gide, Gallimard y Schlumberger. Sin futuro claro, el servicio militar (1921) le aproximó de nuevo a la aviación, y con su título de piloto bajo el brazo marchó a Marruecos, donde descubrió el verdadero desierto, volando casi los mismos cielos que al tiempo surcaba Martínez Esteve ${ }^{8}$. Vuelto a Francia entró en la Compañía Latécoère, cubriendo el servicio postal Toulousse-Casablanca primero y Casablanca-Dakkar después, y tras un accidente pasó su primera noche de soledad bajo las estrellas del desierto del Sáhara, junto a su avión -como Esteve en el Hamad jordano-iraquí-, aventura y sensaciones reunidas luego en dos de sus libros, Courrier Sud y Terre des hommes. El 19 de octubre de 1927 fue nombrado jefe del puesto de la compañía en Cabo Juby. Allí, junto al fuerte español residió casi tres años, llegando a hablar muy bien al árabe ${ }^{9}$, aunque sólo pudo volar en operaciones de rescate de pilotos caídos. Volvió a Francia en marzo de 1929, con la nostalgia del desierto del Sáhara pues "cualquiera que lo haya conocido, allí donde todo en apariencia no es más que soledad y desnudez, evocará sin embargo ese tiempo como el más bello vivido» ${ }^{10}$.

Una vez en París, enseguida le llamaron para las líneas postales aéreas que en Argentina quería montar la Aéropostale francesa, donde se 


\section{Joaquín $M^{a}$ Córdoba}

reunió con sus grandes amigos y camaradas del aire: Mermoz, Reine y Guillaumet. Desde Buenos Aires, Antoine creó la línea de Patagonia y sobrevoló maravillado los Andes, tomando ideas y notas para su Vol de nuit. Asistió también a episodios dramáticos, como la pérdida del avión de Guillaumet y su salvación tras su marcha épica, recogida en Terre des hommes. De vuelta a Francia se casa, la Aéropostale se hunde y recibe premios y distinciones. En 1935, con su mecánico Jean Prévot sufre un accidente en el raid París-Saigón, perdiéndose en el desierto libio. Se les da por muertos. Desaparecidos. Sin agua, sin comunicación, solos en el inmenso desierto de Almásy, ambos emprenden una marcha desesperada hacia el norte. Durante tres días anduvieron sin descanso, pasando las mismas angustias que nueve años atrás Esteve y Calvo sufrieran en el Hamad, hasta que los beduinos les encontraron salvándoles. En diciembre de 1936, su amigo Mermoz, pionero de las aventuras aéreas en el desierto, los Andes y el océano desapareció en el Atlántico. Fue como una premonición de su propio fin. Movilizado en 1939, formó parte de una escuadrilla de reconocimiento, y en junio del año siguiente pasó a Argelia. Huyendo de la Francia colaboracionista se fue a Nueva York; eran los años en los que iba escribiendo Le petit prince, con sus pensamientos, sus vivencias, su tristeza. Publicado en 1943, un año después estaba ya con su escuadrilla de vuelta al combate, y el 17 de julio desapareció con su avión, durante un vuelo de reconocimiento sobre la costa mediterránea francesa. Como dice Nathalie des Vallières, "a bordo de su avión, como el Pequeño Príncipe, partió para volver a su planeta ${ }^{11}$.

Martínez Esteve, Almásy, Saint-Exupéry, los tres salvados de temibles aterrizajes forzosos en estepas inacabables, los tres perdidos donde el silencio no se parece a ningún otro silencio. Sus libros nos evocan hoy los recuerdos del desierto y los cielos en los que al fin hubieron de encontrarse aquellos, en verdad, nuestros tres «aviadores del desierto».

\section{De la vida y destino de un héroe olvidado}

La vida de Rafael Martínez Esteve tiene dos periodos radicalmente distintos, marcados por nuestra Guerra Civil. La primera brillante, entre el valor y la aventura; la segunda triste, marcada por el cautiverio, la separación de los suyos, la pérdida de su carrera y el olvido. Y a diferencia de lo sucedido a Almásy o Saint-Exupéry, nuestro aviador del desierto nunca más volvió a volar. 
Por mucho que lo intentemos, cualquier reseña biográfica apenas si podrá vislumbrar las ilusiones de un joven venido al mundo en Valencia el 17 de febrero de 1894, y la tristeza de un anciano de setenta y un años fallecido en Madrid, el 23 de abril de $1965^{12}$. Nacido en el seno de la bien situada burguesía local, dotado de una intensa curiosidad intelectual y facilidad para las lenguas -llegaría a dominar el inglés, francés y árabe, y a defenderse bien en alemán-, sintió temprana vocación militar. Licenciado en la Academia de Infantería de Toledo en 1914 como Segundo Teniente, tras cortos destinos en la península pasó a Marruecos, participando ya en operaciones y comenzando sus estudios de árabe. Distinguido en numerosas ocasiones y ascendido a Primer Teniente, en 1918 obtuvo sobresaliente en los exámenes de su tercer curso de árabe. Quizás por esa razón le vemos un año después asignado a la Fuerza de Policía Indígena, metido en complicadas acciones de guerra, manteniendo emboscadas, cubriendo retiradas, protegiendo rutas y convoyes o conferenciando dentro del territorio enemigo. Pero ya entonces se había despertado en él la pasión por volar, compartida con la atracción de las montañas del Riff, el desierto y la vida y las costumbres de las gentes de país, con quienes compartía charlas y narraciones junto al fuego. En 1920 volvió a la península, y un año después, en el Aeródromo de Los Alcázares, recibió su título de piloto militar y el grado de capitán. En 1921 se casó con Alicia Vircondelet Gómez, franco-española nacida en Orán, pero África le reclamó. El desastre de Annual obligó a volcar todos los efectivos disponibles, y el ya capitán aviador fue asignado a la Segunda Escuadrilla con base en Tetuán, con sus aviones Breguet XIV -los mismos de la Aéropostale francesa del correo Toulousse-Casablanca-Dakar, volados también por Saint-Exupéry- llevó a cabo numerosas misiones de reconocimiento y bombardeo ligero, fotografía y prueba. En enero de 1924 participó en el vuelo dirigido por el comandante Delgado Brackembury, que trataba de abrir un enlace aéreo entre la península y Canarias, que estaría integrado por un hidro tripulado por Ramón Franco y una patrulla de tres Breguet XIV, mandada por Martínez Esteve. Con escalas en Casablanca, Mogador, Agadir y Cabo Juby, aterrizaron allí los tres Breguet el 8 de enero, esperando la llegada del hidro retrasado. Durante esos días miró las mismas estrellas, soñó y anduvo el mismo desierto que poco después pisaría su camarada francés ${ }^{13}$. De vuelta a su base, nuevas misiones aéreas llenaron su expediente, las más de las veces muy arriesgadas. Y es que la aviación de entonces tenía que descender a tiro de fusil para conseguir sus objetivos, que en demasiadas ocasiones consistían en introducir municiones, comida, hielo o medicinas 


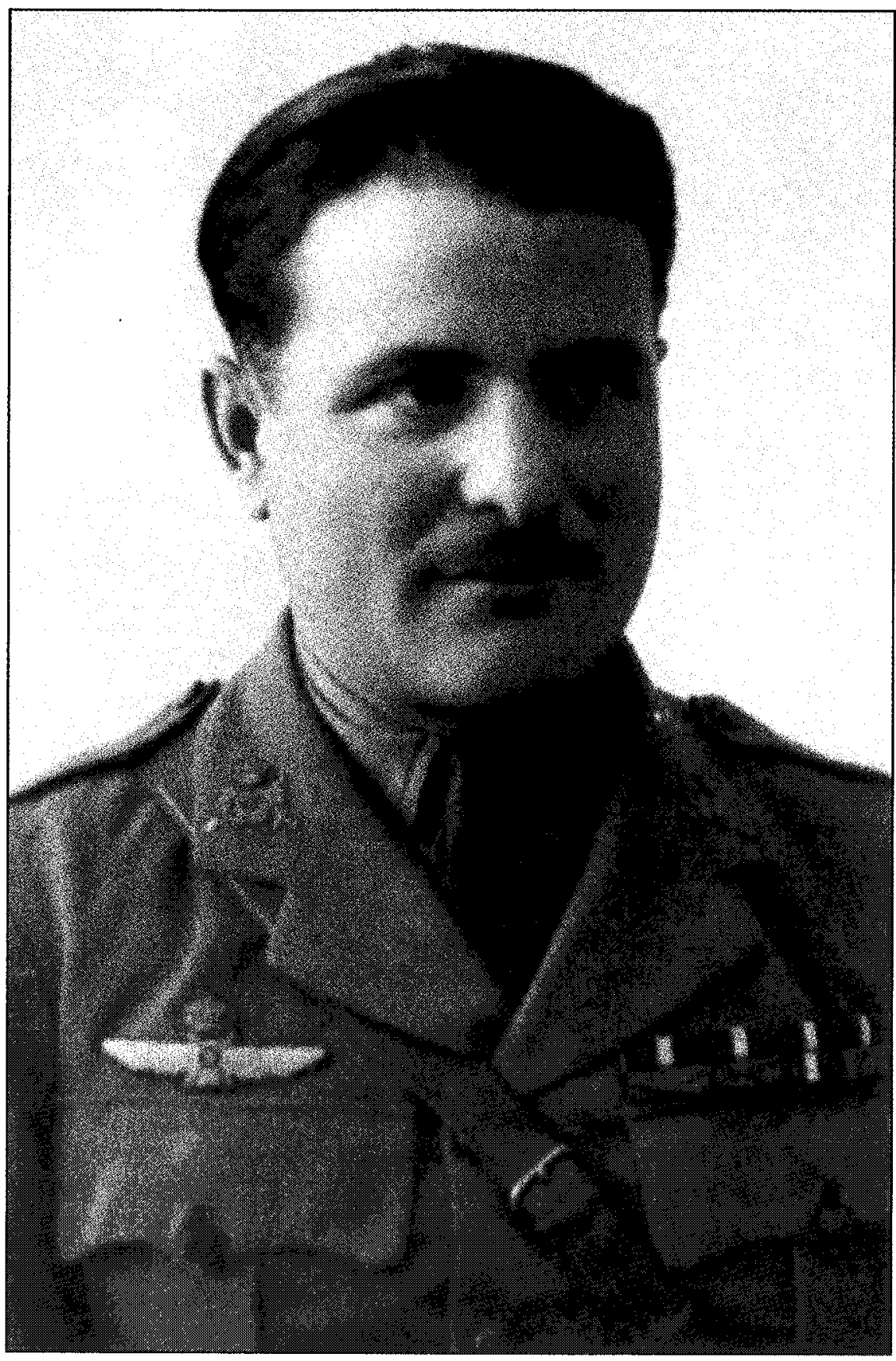

Figura 1. Fotografía del capitán Rafael Martínez Esteve, en la época del vuelo Madrid-Manila (según J. Sánchez Méndez, 2001, p. 126) 
casi «a mano» en el interior de posiciones asediadas: era el llamado "vuelo a la española» ${ }^{14}$. En una de esas operaciones cayó el capitán Joaquín Boy Fontelles, extraordinariamente popular entre sus compañeros, que en el auxilio a la famosa posición asediada de Tifarauin ${ }^{15}$ murió derribado por fuego de fusilería en su segunda pasada sobre la posición. Camarada y amigo de nuestro biografiado -como Ramón Franco, Llorente y tantos otros que formaban la peculiar hermandad de los aviadores de entonces-, a su memoria y a la de su observador, el también capitán Baeza, dedicaría Esteve sus recuerdos de aventura en el desierto jordano-iraquí.

En 1924, con su compañero capitán Joaquín Loriga, y recogiendo una idea del fallecido capitán José Carrillo Durán, redactó una memoria sobre un posible vuelo "Madrid-Manila», que como otros serían pospuestos hasta la conclusión de la guerra de Marruecos. Mientras tanto, ambos siguieron soñando con su plan. En julio del mismo año Esteve fue derribado en las maniobras de aprovisionamiento a la posición de Cobba, y tras conseguir un aterrizaje forzoso en territorio enemigo, quemó el avión para que no cayera en sus manos y se abrió paso a tiros junto a su observador hasta las líneas españolas. Finalizada la guerra con el desembarco de Alhucemas, el gobierno español aprobó para 1926 tres vuelos a larga distancia, los primeros grandes raids de la aviación española. A punto de quedar fuera del proyecto por enfermedad, Martínez Esteve consiguió incorporarse in extremis y partir para el vuelo que marcaría definitivamente su vida.

Acabada la aventura y de vuelta a España, propuso una "Memoria de un vuelo transatlántico" sin escalas, con el mismo tipo de avión Breguet XIX usado en el vuelo a Manila, y que habría de ser preparado especialmente. Anterior al proyecto de Charles Lindbergh ${ }^{16}$, el plan fue rechazado por el gobierno de la Dictadura. Desde entonces, entre Esteve y sus superiores empezaron a darse frecuentes roces, que acaso decidieron la orientación política posterior del aviador. En todo caso, su carrera siguió sumando a varias condecoraciones, el ascenso a comandante por méritos de guerra en 1927, y prestando servicio en distintas bases y grupos de vuelo. Una nueva aventura, la vuelta al mundo en un cuatrimotor Dornier montado en Cádiz, a la que fue invitado por el jefe de la misma, Ramón Franco, se frustró porque el gobierno desaprobó su presencia, siendo sustituido por Eduardo González Gallarza. El vuelo no se llegó a realizar, pero el desaire acentuó su enfrentamiento con la Dictadura y la Monarquía. Separado del servicio, sancionado nuevamente en febrero de 1931, con la República se reintegró a la aviación, pasando por Getafe, Marruecos y Sevilla, donde al mando de la base aérea de Tablada y cuan- 
do estaba a punto de ascender a teniente coronel, le sorprendió el levantamiento del 17 de julio de 1936. Comenzó entonces la segunda parte de su vida.

Los hechos acaecidos en el aeropuerto durante los días 18 y 19 , que cercenaron su carrera y su vida familiar, se desarrollaron con una extraordinaria rapidez. La mañana del 18 llegaron a la base tres aviones Douglas de las Lineas Aéreas Postales Españolas, que aviadores del gobierno querían usar como bombarderos en Marruecos. El capitán Carlos Martínez y Vara del Rey, afecto al alzamiento, quiso impedirlo averiando con sus disparos el motor de uno de ellos. Tripulantes y soldados le hicieron frente e hirieron, y cuando estaban a punto de matarle, el comandante Esteve se interpuso pistola en mano, llevándoselo a un despacho donde le encerró y puso bajo guardia de su confianza. Queipo de Llano le llamó por teléfono pidiéndole su apoyo, pero Esteve no quiso, alegando que se lo impedía "su dignidad" y su juramento de fidelidad. Al no cumplir tampoco la orden gubernamental de bombardear los barrios de Sevilla por los que se movían los sublevados -por el temor a ocasionar una matanza entre la población civil-, el capitán Antonio Rexach le entregó la orden gubernamental de su retiro del mando. Lo que después pudo haber pasado con él lo ignoramos, porque los nacionales tomaron la base al anochecer del 19 de julio, y responsabilizado Esteve de los bombardeos sobre Tetuán y Larache, fue detenido y sometido a un Consejo de Guerra, resultando expulsado del ejército -en su expediente personal se dice (sic) por "rrebelión militar»- y condenado a muerte el 20 de septiembre del mismo año, a pesar de la defensa que de él hicieran el capitán Carlos Martínez y Vara del Rey y otros compañeros del arma, así como la evidencia de que había impedido los bombardeos sobre Sevilla.

Preso allí, conmutada en octubre la pena de muerte por la de treinta años de prisión mayor, su esposa hizo cuantas gestiones pudo para conseguir su liberación, pero en noviembre del mismo año fue trasladado al Castillo de Santa Catalina en Cádiz. Alicia, desesperada, valiéndose de su pasaporte francés, cogió a sus hijos y pasó a zona republicana en 1937, quedándose ella en Barcelona y mandando a los niños a Rusia como tantos otros refugiados. Luego se fue a Francia, y cuando proyectaba ir a la URSS para recoger a sus hijos estalló la II Guerra Mundial. Recluida en un campo de concentración, no sabemos cómo consiguió volver a España, reuniéndose en Valencia con las hermanas de su esposo. Mientras Esteve cumplía condena, y distraía su angustia profundizando su alemán, pues en cartas conservadas en su expediente y dirigidas a su hermana Vicenta, le pide libros y revistas en esa lengua "o en inglés y si no hay en 
francés", que encontraría en la Librería Extranjera de la Plaza de Santa Ana de Madrid. Los amigos y compañeros de siempre y el incansable capitán Carlos Martínez y Vara del Rey seguían con sus gestiones para conseguir atenuar su condena: de hecho, el 20 de julio de 1943 se le conmutó por otra de veinte años de reclusión menor, iniciándose además un expediente de libertad condicional, concedida en septiembre de 1943. Salió libre el 1 de octubre, y ambos esposos se reencontraron fuera de la prisión, llorando la lejanía de sus hijos. Pero Alicia estaba muy enferma, y operada de una dolencia cardíaca en Sevilla murió prematuramente en 1945, a los cuarenta y cuatro años de edad.

Un año después, Rafael Martínez Esteve fijó su residencia en Madrid. En 1956 tuvo la inmensa alegría de reencontrarse con dos de sus hijos vueltos a España, Rodolfo y Alicia, pero murió el 23 de abril de 1965, sin haber logrado volver a ver a los otros tres. Era un héroe olvidado.

\section{La época de los retos: el vuelo Madrid- Manila y su paso por Bagdad e Irán}

Con la finalización de la guerra en Marruecos y sobre todo con la autonomía y el enorme desarrollo propiciado por las reformas de Kindelán ${ }^{17}$, la aviación española pudo pensar en participar en los grandes raids y los desafíos de vuelo que otras aviaciones estaban llevando a cabo hacía tiempo. El año 1926 marcó el principio de nuestros grandes retos, con tres vuelos espectaculares y exitosos: en enero, el hidroavión Plus Ultra cubrió los $10.270 \mathrm{Km}$. que separan Palos de Moguer y Buenos Aires en 59 horas y 39 minutos de vuelo. Ramón Franco, Julio Ruiz de Alda, Pablo Rada y Juan Manuel Durán saltaron de golpe a la fama. Luego, en abril estarían en el aire los tres Breguet XIX de la «Patrulla Elcano", para un vuelo de $17.950 \mathrm{Km}$. hasta Manila, a donde sólo llegó el avión pilotado por Eduardo González Gallarza. Pero tanto él como los demás miembros de la patrulla, Rafael Martínez Esteve, Joaquín Loriga y sus mecánicos se convirtieron en otras tantas celebridades. Finalmente, en diciembre despegó la patrulla "Atlántida», tres hidroaviones Dornier que al mando del comandante Rafael Llorente efectuaron el vuelo desde Melilla a Santa Isabel en Guinea y vuelta, totalizando $13.932 \mathrm{Km}$. de vuelo en doce etapas a la ida y nueve en el retorno. Por esta hazaña Llorente recibió "el segundo premio del Congreso de la Liga Internacional de Aviadores que otorgó el primero a Charles Lindbergh ${ }^{18}$. Pero centrémonos en el vuelo Madrid-Manila. 
Como apunto más arriba, la idea original se había gestado durante el invierno de 1923-1924, pero su promotor -capitán José Carrillo Durán- murió en combate en septiembre del veinticuatro. Sus amigos y compañeros, Joaquín Loriga y Rafael Martínez Esteve la hicieron suya, presentando un mes después una memoria sintética que fijaba temas como los aviones, altura de vuelo, carga recomendada, recambios, época del vuelo más aconsejable, ruta, distancia y duración de las etapas, aeródromos de apoyo, presupuesto y razones de la propuesta ${ }^{19}$. Por fin, tras algunas contrariedades y retrasos, el 8 de abril de 1926, a las 8,15 de la mañana despegaban del aeródromo de Cuatro Vientos los tres aparatos Breguet XIX, pilotados por los iniciadores Esteve y Loriga, y por el comandante Eduardo González Gallarza, acompañados respectivamente por sus mecánicos Pedro Mariano Calvo, Eugenio Pérez y Joaquín Arozamena. La primera etapa, Madrid-Argel, era de $900 \mathrm{Km}$.: la segunda, Argel-Trípoli de $1.300 \mathrm{Km}$. Durante la tercera, TrípoliBengasi de $950 \mathrm{Km}$., a pesar de volar a $2.500 \mathrm{~m}$ de altura sufrieron los remolinos del desierto, que zarandearon los aviones sin piedad. Los $1.150 \mathrm{Km}$. de la etapa a El Cairo se hicieron en ocho horas de vuelo. Punto de pausa obligada, mientras se revisaban sus aparatos visitaron la ciudad y sus curiosidades. Y el 11 de abril despegaron a las 15,40 horas camino de Bagdad, peligrosa y muy larga quinta etapa con sus $1.400 \mathrm{Km}$., volados en parte por uno de los mayores desiertos de la tierra. Para no perderse tenían que seguir las marcas hechas en tierra por la aviación inglesa, y atenerse a los consejos del aviador británico Allan Cobhan, que Gallarza y Loriga recuerda en su libro ${ }^{19}$. Ambos pilotos escribirían luego que "a poco de habernos internado en la peligrosa inmensidad de este vasto desierto, vimos perderse entre remolinos de arena y nubes a Esteve. Seguía nuestra misma dirección, y abrigábamos la esperanza de encontrarlo más adelante». El vuelo siguió hacia Bagdad, que describen desde el aire, unida entonces sólo por un puente de barcas de unos doscientos metros. Preocupados por la tardanza de Esteve retrasaron la salida, pero el 13 hubieron de partir -los monzones se acercaban y las grandes tormentas de arena estaban alcanzando Basra-, y tras rogar a los británicos la búsqueda de sus camaradas despegaron rumbo a Bushir. Siguieron el curso del Tigris hacia el sur, luego por la llanura llegaron a la costa y a Bushir, y el mismo día alcanzaron Bandar Abbás, donde siglos atrás había desembarcado el embajador español Don García de Silva y Figueroa. Inesperadamente, la historia de los viajeros españoles a Oriente se reencontraba allí. Luego el vuelo siguió adelante y vivió asombrosas aventuras, alcanzando por fin $\mathrm{Ma}$ - 
nila el 13 de mayo, siendo recibidos por 12 aviones de Estados Unidos que, como escolta de honor, les acompañaron hasta su aterrizaje a las 11,20 de la mañana. Una marea humana se abrió paso hasta el avión. Lo habían conseguido.

Dos años después, con un gran aparato Breguet tipo «Gran Raid», fabricado en España -el famoso "Jesús del Gran Poder», hoy conservado en el Museo del Aire de Madrid-, los capitanes Jiménez e Iglesias intentaron batir el record mundial de distancia sin etapas, llegando a Pakistán. Despegaron de Tablada el 29 de mayo de 1928, pero una avería causada por la arena les hizo aterrizar en Nasiriyah, junto al Éufrates, tras 5.100 $\mathrm{Km}$. muy meritorios de vuelo continuado, que si no les permitieron batir el ansiado record ${ }^{20}$, sí que otros dos viajeros y aventureros españoles del siglo XX llegaran hasta el corazón de Mesopotamia.

Pero volvamos a Esteve y su aventura, porque si su persona merece un puesto en la historia de la literatura española de viajes a Oriente es, precisamente, porque tras sufrir un aterrizaje forzoso cubrió muchos kilómetros por aquel inmenso desierto, y supo describir luego su aventura en un libro que resulta hoy una bella evocación de aquella época gloriosa de viajeros, aventureros y eruditos enamorados de Oriente, curiosamente cerrada por esa saga de «aviadores del desierto».

\section{Otro viaje a Oriente: una aventura en el desierto}

El mismo año del vuelo hasta Manila publicó el capitán Rafael Martínez Esteve, en la editorial Espasa Calpe de Madrid, el libro que recoge su epopeya, Una aventura en el desierto. Para la literatura de viajes es un libro algo extraño, porque es fruto de una avería y no de un plan preconcebido, aunque su autor estuviera más que preparado por su experiencia en Marruecos y su dominio del árabe, sin contar su manejo del inglés y el francés. El librito original es de pequeño formato, e incluye además de algunos croquis y fotografías en blanco y negro, una serie de atractivas ilustraciones firmadas por A. Llorente, y una bella portada del mismo autor, que recoge la angustiosa situación del piloto y su mecánico junto al avión en tierra, y recuerda ligeramente la cubierta puesta luego a la edición de Terre des hommes, de A. de Saint-Exupéry, en Le Livre de Poche publicada en París en 1971. Voy a seguir el viaje y marcha de Martínez Esteve omitiendo las referencias de nota salvo causa mayor, pues la continuidad del relato facilitará la localización de cualquier consulta interesada en su propio texto ${ }^{21}$. 
Comienza el libro de nuestro aviador con una invocación al «nido de águilas" de Tetuán, donde se formó la aviación militar española en la Guerra de Marruecos. Luego, al igual que sus compañeros Gallarza y Loriga harían en su propio libro El vuelo Madrid Manila, detalla la preparación del raid aéreo y sus condiciones. Se eligieron los aviones Breguet XIX A2, empleados ya por la aviación militar y considerados los más adecuados. Dos, acondicionados especialmente en la fábrica de Paris: el tercero, de serie normal, se adaptó en lo posible en el mismo Cuatro Vientos. Esteve pilotaría este avión, del que se conserva una excelente maqueta en el Museo del Aire de Madrid ${ }^{22}$. Cada avión llevaba como armamento para defenderse en caso de aterrizaje, un rifle automático, una pistola y 200 cartuchos para cada arma. Lejos estaba entonces el mecánico Calvo de saber, que el último disparo de aquella pistola le salvaría la vida. Como instrumentos de navegación sólo podían llevar una brújula Hughes y un corrector de deriva, lo que no excusaba como era norma entonces, la continua atención a los planos y su cotejo con el relieve. Por fin, el día 5 de abril la escuadrilla despegó a primera hora de la mañana "envueltos en una ligera neblina ...hasta que ...el sol rompe los jirones de la bruman. Luego Esteve iría describiendo el paisaje español, la costa y el vuelo sobre la belleza del azul Mediterráneo. Ya sobre África entraron por el valle de Chelif, dirigiéndose hacia Argel volando a $200 \mathrm{Km}$. por hora, sobre un paisaje de llamativo verdor. Los militares franceses les recibieron con extrema cordialidad, y como sería norma en todas las etapas del viaje, la colonia española se esforzó por agasajarlos. Al día siguiente despegaron con niebla, y rumbo a Túnez comenzaron los problemas. A los pocos minutos los aviones se separaron, pues tenían que volar o a $10 \mathrm{me}$ tros del suelo o por encima de la niebla. Esteve subió para evitar el peligroso terreno montañoso, pero pronto tuvo que buscar la costa para no perderse: volando a 10 metros del agua y muy cerca de la orilla, sorteando los obstáculos, disfruta con el vuelo; pero al mirar el estado del combustible nota que ha consumido 170 litros jen una hora!. Preocupado, continúa suponiendo que sufre una pérdida que sólo podría arreglar en tierra. Pero el combustible se volatiliza rápidamente, por lo que ha de tomar tierra en Túnez. Sus compañeros continuarían vuelo hasta el fin de la etapa del día, prevista en Trípoli. En Túnez recibió la misma cordialidad de franceses y españoles, llevándose como recuerdo la gentileza de una dama francesa, que le obsequió un ramo de flores que le acompañaría hasta quedar marchito en el desierto jordano-iraquí, y las dulces canciones de una joven tunecina, que le trajeron a la memoria la primera casida de amor escuchada a un nómada del Sáhara, en una no- 
Aviadores en el desierto...

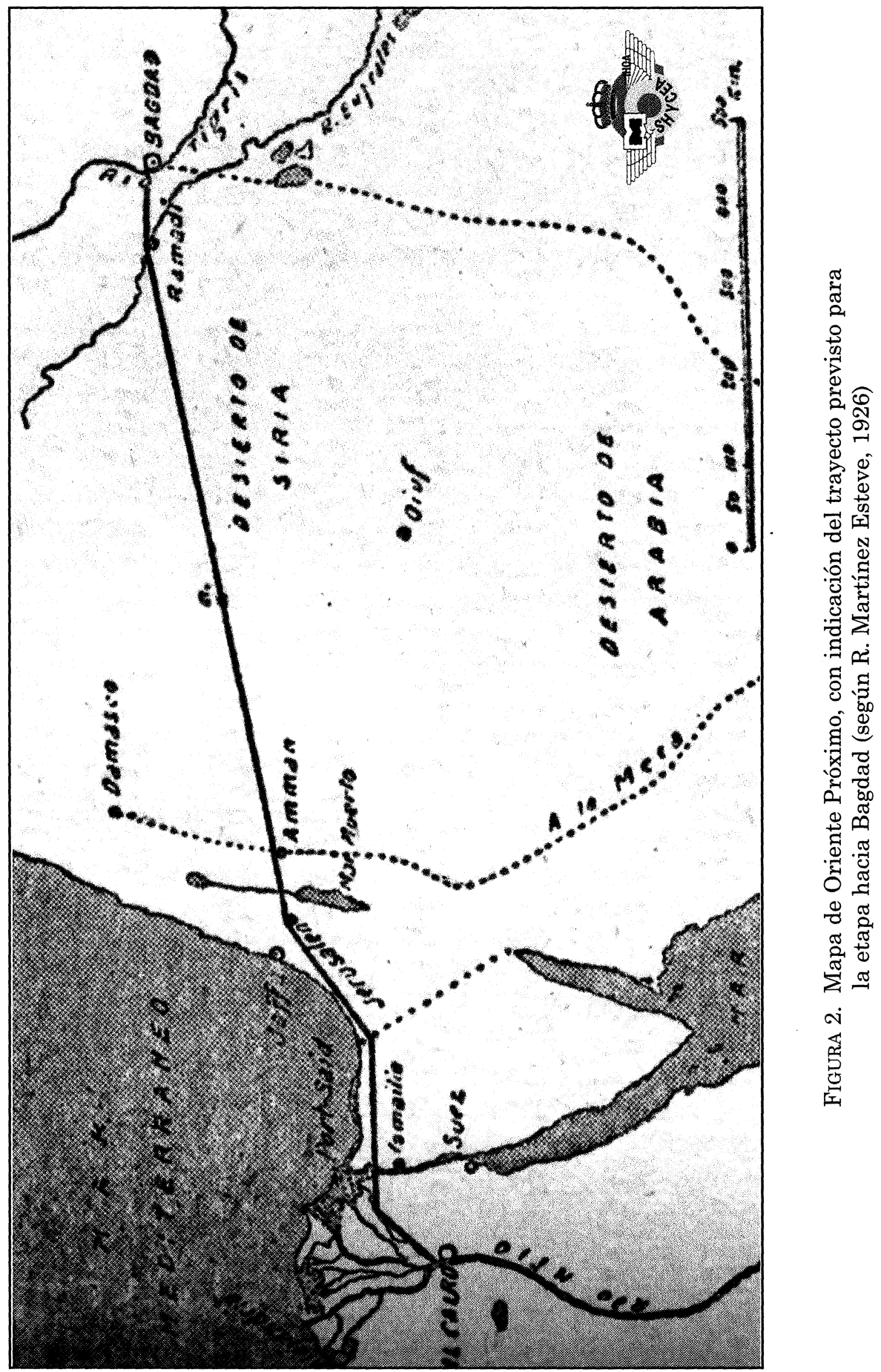


che estrellada vivida tiempo atrás en el oasis de Aïn-Sefra. El vuelo continuó al día siguiente hacia Trípoli, pero el mal tiempo se cebó en su avión cazándolo en una tormenta que le sacude y provoca bruscos descensos de 300 metros o subidas de 2000 . Varias veces está a punto de entrar en barrena, y cuando todo iba a peor desapareció de repente la tormenta, descubriendo que estaba ya en la costa de Gabés, a unos $800 \mathrm{Km}$. de Trípoli, donde por fin llegó acogido con toda simpatía por los oficiales italianos. Un mensaje de Loriga le dice que le esperarán en El Cairo, tal y como previamente habían acordado en caso de retrasos de algún avión.

Cuando despegó de Trípoli, Esteve recordó un fragmento de Las mil y una noches, en el que el príncipe Nur Addin dice wviajar, renovarse, esperar sensaciones nuevas, el placer de la vida está en el movimienton: y su aparato voló sobre el golfo de la Gran Sirte. Una vez en Bengasi, estudió el itinerario atentamente y despegó a las 8 de la mañana del día 9 de abril. Pronto se encontraría volando por el inmenso desierto de Libia, que poco después iba a explorar por vez primera el otro gran aviador del desierto, László Almásy; "a nuestra derecha, interrumpiendo la monotonía de la inmensa sábana de arena, se levantan de trecho en trecho pequeños montones de piedra, de color obscuro". Al fin, horas después alcanzaron el valle del Nilo, y Esteve distinguió a sus pies "los rojizos minaretes de las viejas mezquitas de El Cairo; a nuestra izquierda se yerguen las pirámides la esfinge, en una amarillenta llanura de dunas de arena". Aterrizó en la base aérea de Heliópolis, acogido por las autoridades diplomáticas españolas. Ni las británicos, ni los egipcios enviaron representación alguna, y Esteve tuvo sus primeros roces con el oficial inglés de servicio en el aeródromo y, lo que sería peor en el futuro, con el embajador español, molesto ya con sus compañeros Loriga y Gallarza. Reunidos por fin, los tres aviadores llevan a cabo las habituales visitas protocolarias, continuadas en las pirámides y museos, y Esteve comienza sus curiosas observaciones sobre el colonialismo británico y la formidable organización de su aviación desplegada en Oriente. El día 11 despegaron los tres aviones a las siete de la mañana. Tras cruzar el Canal de Suez sobrevolaron Palestina, donde uel paisaje es triste y monótono, a nuestra izquierda el mar, a la derecha el desierto arenoso del Nefudn. A la vista de Amman se dispusieron a cortar el desierto siguiendo la ruta señalada por la aviación británica, y se introdujeron en él. Esteve sintió primero algunos problemas menores que no le preocuparon, pero a las cinco horas de vuelo hacia Bagdad el motor cesó de funcionar, y en pocos segundos tuvo que elegir dónde aterrizar forzosamente. Su viaje aéreo por Oriente había terminado. Comenzaba entonces -aunque todavía lo 
ignoraran, confiados en la buena organización inglesa-, su tremenda aventura y marcha por la inmensidad del Hamad.

Esteve y Calvo estudiaron el motor y descubrieron la causa del fallo; se habían quedado sin combustible por una grieta en el remache del amortiguador de presión. Pero subsanada la avería se vieron en la imposibilidad de continuar, dada la falta de gasolina. Era preciso actuar rápido, y en breves instantes prepararon un fuego cuyo humo había de verse a muchos kilómetros. Sobre la ruta marcada por los ingleses colocaron un largo lienzo blanco, y se mantuvieron a la espera confiando en que ya les estarían echando de menos y quizás incluso buscándoles. A las cuatro horas oyeron ruido de motores y se alegraron ante su inmediato rescate, pero los aviones pasaron de largo sin verlos. Calvo preguntó en voz alta asombrado "zpero es posible que no nos hayan visto?". El humo, las señales sobre la ruta, el gran avión Breguet pintado de verde sobre la estepa, ... Y Esteve escribe que comenzó entonces a germinar en su alma una terrible sospecha. Pasaban las horas y se puso a inspeccionar los alrededores, descubriendo el armazón de un avión quemado, huellas de distintos animales, el camino clásico de las caravanas y los restos de un campamento beduino que, como era habitual en él, le hizo imaginarse experiencias pasadas: "reconstituyo mentalmente la escena; veo a los beduinos encender fuego y hacer la oración mirando a Oriente; a los camellos en círculo rumiar las hierbas del desierto ...". Otra patrulla inglesa pasó sin verlos, y mientras la noche se les echó encima, así que se arrellanaron en sus puestos del avión y se abrigaron en lo posible con sus trajes de vuelo. El frío era terrible, y la noche animaba inquietantemente la vida del desierto; "en la obscuridad de la noche vemos el brillo de muchos ojos que parecen interrogarnos". Estaban al norte del inmenso Nafud, en el propiamente llamado Hamad, la inmensa llanura lisa y pedregosa, vacía de vida, azotada por los torbellinos de polvo y arena, que apenas si cruzaban algunos beduinos, siguiendo los contados pozos existentes. Al amanecer, Esteve calculó su posición, creyendo encontrarse próximo al aeródromo de urgencias marcado en la ruta inglesa con la letra M. En dirección a Bagdad, los pozos más próximos estaban a unos $160 \mathrm{Km}$.; en la de Amman, a unos 200, pero los beduinos estaban acampados en esa dirección, y Esteve confiaba instintivamente más en ellos que en los británicos. Un día más, las patrullas inglesas pasaron por encima sin divisarlos. Hasta ocho pasaron por encima, a menos de 200 metros de altura, ante el asombro y la rabia de Esteve: «aquella torpeza inglesa rayaba en lo inconcebible; si nuestros espíritus no hubiesen estado templados para la lucha, hubiésemos muerto alli mismo de ira y desesperación". Y decidieron partir 
en busca de ayuda. Cogieron tres termos con litro y medio de agua, y algo más en un neumático, ingeniosamente preparado para ello. Además, sus armas de fuego, un cuchillo de monte, zapatos de repuesto, dos pares de calcetines, un plano y media manzana, que era en suma todo su «bagaje para cruzar el desierto». Tras dejar notas escritas en francés, español, inglés y árabe en el avión, indicando la ruta que iban a seguir y los medios con que contaban, se pusieron en camino.

Cualquiera que tenga un cierto conocimiento de los distintos desiertos convendrá en que uno de los más desasosegantes es el Hamad, la gran planicie que se extiende entre Transjordania y el valle del Éufrates. La monótona y aplastante regularidad de la inmensa llanura, pedregosa a veces, es desoladora hasta extremos difíciles de explicar. Al menos a mí siempre me ha resultado así, en las ocasiones en que por fuerza he tenido que viajar por él. Por eso ahora siento más cercano el horror de su marcha, y comprendo el enorme valor y el coraje que Esteve y su mecánico demostraron al decidirse a cruzarlo en busca de los beduinos. $\mathrm{Al}$ atardecer empezaron a andar por la ruta inglesa, descansando cada treinta minutos para ahorrar fuerzas. Venida que fue la noche siguieron andando confiados, mirando a veces las estrellas y constelaciones que brillaban en lo alto. Al amanecer bebieron y comieron el resto de su manzana, pero no sabían a qué altura podían encontrarse, al no distinguir referencia válida alguna. Pronto empezaron a sentir algo de la verdadera dureza del Hamdd: el jamsin. La temperatura subió enormemente y la arena se levantó en remolinos, convirtiéndose en una feroz tormenta que formaba "ráfagas (que) pasan con la velocidad del huracán". Tuvieron que arrojarse a tierra para resistirlas, envolviéndose la cabeza en sus guerreras. Amainada algo la fuerza de las oleadas, se levantaron y volvieron a caminar, pero a poco hubieron de echarse de nuevo al suelo. Así pasaron horas de marcha agotadora, sufriendo además un calor insoportable. Al anochecer mejoró la temperatura y se dispusieron a descansar. Escribiría luego Esteve de aquel día que "la jornada ha sido muy dura, y pienso que de seguir soplando el jamsin no pasaremos del día siguiente». Calvo empezaba a sentir la sed, pues agotada el agua de los termos, la del neumático resultó de un sabor terrible. Los labios se les agrietaron, y mientras el mecánico dormía Esteve contempló absorto el "maravilloso crepúsculo del desierto cruel e inhospitalario, lugar de maldición y de odion. Prosiguieron la marcha, pero Calvo resistía cada vez peor, y ambos tuvieron alucinaciones espantosas. Durante el día los cuervos les seguían por un camino "sembrado de osamentas de camellos y gacelas; todo conspira en con- 
tra nuestra; todo llama a la muerte, y el alma se prepara para el gran viaje, para el último vuelon. Así pasaron días, aunque perdieron la noción del tiempo. $\mathrm{Y}$ un atardecer, cuando Calvo descansaba profundamente dormido, para calmar sus nervios se puso Esteve a explorar los alrededores, encontrando un pequeño lago de aguas de lluvia. Al volver sobre sus pasos para darle la alegre noticia a su compañero, no le halló. Al despertarse solo, intranquilo por su ausencia, Calvo debía haberse puesto a buscarle, y ahora se habían perdido mutuamente, con el agravante de que Esteve quedó sin arma ni agua alguna. Tras dos horas de perplejidad inactiva decidió seguir andando, confiando en que el mecánico que aún disponía de agua, no se movería de la zona. Él debía buscar urgentemente la ayuda necesaria, y como pensaba que no debía estar lejos de los pozos y los beduinos, caminó durante la noche. $\mathrm{Al}$ amanecer percibió un cambio notable del paisaje. Probablemente estaba en las estribaciones del desierto basáltico jordano, según su descripción. Por su vertical, dos aviones ingleses pasaron sin divisarle, aunque agitó su camisa varias veces. Siguió caminando, mas la sed le atormentaba, y las heridas de los pies le obligaron a quitarse los zapatos de repuesto y caminar descalzo. Al principio se sintió mejor, pero luego piedras y espinos aumentaron su martirio. La sangre se coagulaba y los pies se le deformaron "llenos de espinos, de barro $y$ sangre", pero al final consiguió andar con rapidez. Una voz le empujaba a andar, a llegar pronto. Abrumado por el călor, a las dos de la tarde no encontró refugio alguno, y empezó a sentir deseos de renuncia, de dejarse ir. Echado en el suelo, su vista se cruzó con la de una serpiente que, muy cerca de él, le miraba fijamente. La escena me recuerda el encuentro del pequeño príncipe con la serpiente que le ayudó a partir. Medio inconsciente, Esteve la miró a su vez -como escribió luego- con alegría, «pues en aquella soledad deseo la compañía de los seres vivos", y tras algunos pensamientos curiosos, agotado y "presa mi alma por el deseo de la muerte" extendió el brazo a la espera de que la serpiente pusiera fin a sus sufrimientos. Pero ella se apartó: insistió Esteve y su curiosa amiga, tímida, se escondió en su guarida. Comenzó luego a tener alucinaciones, creyéndose acompañado en su marcha por una figura que supuso ser el destino. Durmió agotado sobre el suelo, y al despertar se encontró rodeado por una manada de hienas:que espantó como pudo. Continuó andando, poseído por la fiebre, sediento, pero avivando el paso sin cesar y al atardecer, los aviones ingleses le descubrieron por fin, produciéndose la escena con la que comenzaba mi evocación de esta tremenda aventura. 
Tras el rescate, al principio le resultaba imposible beber, dado el estado de su boca y su garganta. Pero había pasado la angustia, y los ingleses le curaron sus llagados pies y le procuraron un lecho confortable. Había que dormir esa noche en el desierto. Los dos oficiales británicos se echaron junto al español, y los tres estuvieron charlando de asuntos diversos, prometiéndole que al amanecer buscarían a Calvo; incapaz de dormir, Esteve asistió despierto a un nuevo e impresionante amanecer en el desierto. A poco de salir el sol, los ingleses le trasladaron a un aeródromo provisional, cercano a Amman, donde fue atendido por un joven médico canadiense. Pero Esteve no podía tranquilizarse, acongojado por la suerte de su mecánico. Por fin le comunicaron que había sido encontrado, aunque como Calvo le contó después, agotado ya y sin fuerzas, caído en el suelo e ignorado por dos pilotos que acababan de aterrizar a unos cientos de metros, consiguió llamar su atención con el disparo hecho con la última bala de su pistola..

Una vez en Amman envió un telegrama anunciando la continuación de su viaje a Manila, y fue recibido por el rey Abdallah en su palacio, levantado por los ingleses en una de las colinas de Amman. Ambos mantuvieron una conversación animada, gracias al buen árabe del aviador español, que conoció por boca del hermano de Faysal muchos incidentes que ignoraba, y que le confirmaron que su idea de buscar la ayuda de los beduinos había sido la mejor decisión. Pero estando en animada charla con el rey recibió la respuesta a su telegrama; tenía que volver a España. Abatido, Esteve se dispuso a obedecer una orden que le parecía inexplicable.

El 23 de abril, tan solo once días después de su forzoso aterrizaje en el desierto, los británicos llevaron a los aviadores españoles hasta su aparato, que encontraron custodiado por una tribu beduina, según órdenes del rey Abdallah. La recarga de gasolina se tuvo que hacer lentamente, finalizándose apenas una hora antes del crepúsculo. Contrariado por tener que pasar allí la noche, el jefe de la patrulla británica le dijo que saldrían al amanecer, disponiendo su campamento según las normas reglamentarias, como si pudieran ser atacados. Pero Esteve prefirió acercarse a los beduinos y pasó la noche en amena conversación con ellos, agrupados a su alrededor y junto a un fuego. "¿Cómo pudiste resistir tanto?. Si hubieras tenido un camello ...", le dijo el scheij. Y hablaron de mil cosas, y se hicieron miles de preguntas amistosas. Reunidas en torno a una hoguera próxima, las mujeres beduinas miraban con curiosidad la escena, escuchando atentas y riendo a veces de lo que hablaban los hombres. Y Esteve escribiría después admirando su belleza, su gracilidad, 
Aviadores en el desierto...

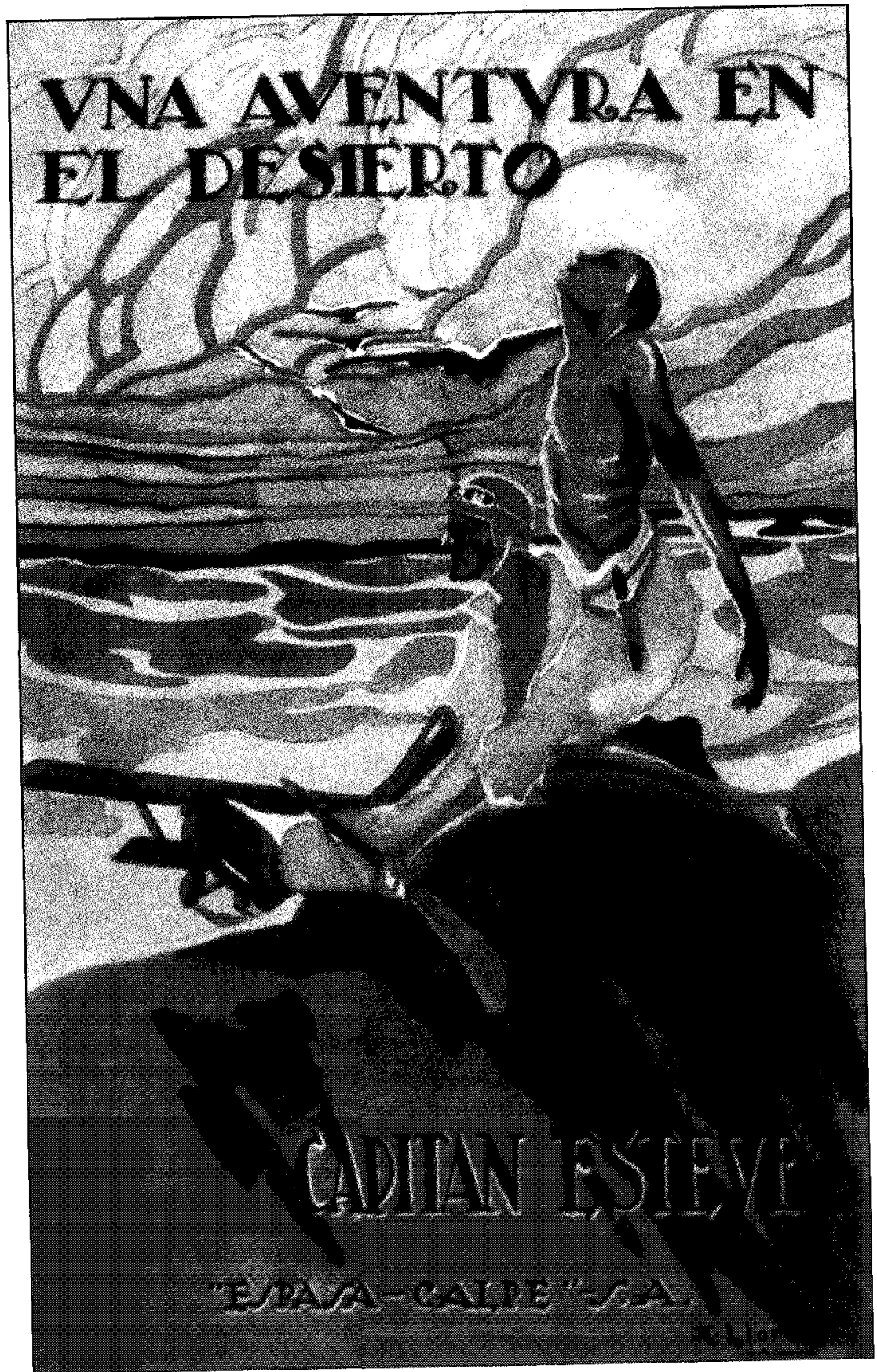

Figura 3. Portada para la primera edición de Una aventura en el desierto, realizada por A. Llorente 
sus vestidos y sus joyas, su rostro orgullosamente descubierto. La aventura se estaba terminando. $\mathrm{Al}$ amanecer, todos los aviones despegaron, $\mathrm{y}$ pocos días después el sufrido Breguet XIX emprendió su vuelo de retorno. En la carlinga, Esteve pensaba mirando el paisaje: «el silencio del desierto ... ¿ Conocéis algo más elocuente que el silencio absoluto en la llanura sin fin?...; silencio obra de siglos". Aunque él se sintiera fracasado, lo cierto es que acababa de escribir su nombre en la selecta hermandad de los ascendidos a la fama eterna.

\section{Epílogo: de arcángeles y aviadores, de príncipes y desiertos}

Nathalie des Vallières subtitula su biografía de Antoine de SaintExupéry como "el arcángel y el escritor". Y en la vida, la muerte y los pensamientos de nuestros tres grandes aviadores del desierto, se me antoja que hay algo de arcángeles - tan cerca de las estrellas y enamorados del cielo-, y un mucho de escritores, amantes de los libros y de escribir sus recuerdos. Los tres se fueron poco a poco, en orden inverso a como habían llegado a la tierra. Primero Saint-Exupéry, desaparecido en un vuelo de guerra, a los 44 años de edad. Después Almásy, a los 57, de vuelta a casa y con la luz del desierto todavía en los ojos. Y al fin Rafael Martínez Esteve, mucho más tarde, con 71 años, lejos del desierto y los cielos que surcó. Pero no fue su muerte la más triste, o al menos yo creo que no.

Todos hemos leído $E l$ pequeño príncipe, y sabemos bien que para volver a su planeta, necesitaba el niño dejar atrás el cuerpo con el que andaba por el desierto en compañía de un aviador perdido. Y que una serpiente amarilla, a la que conoció al principio de su llegada, le ayudó finalmente a partir. Pues bien, el 23 de abril de 1965, Rafael Martínez Esteve dejó caer una vez más su brazo en la cama, como décadas atrás lo hiciera en el desierto. Pero esta vez su amiga se apiadó de él, ayudándole a abandonar como al pequeño príncipe, el cuerpo que le impedía volar.

\footnotetext{
Notas

* Agradezco las informaciones facilitadas y la amabilidad con la que han atendido mis consultas los descendientes del coronel Rafael Martínez Esteve, en particular su nieto don Alejandro Martínez-Esteve Melnikov. Del mismo modo y de todo corazón, los materiales y la información que me prestó el Director del Museo del Aire, Excmo. Sr. General Don Luis Castañón Albo. Igualmente agradezco las noticias, atenciones y materiales que me dio a su vez el comandante don Juan M. Riesgo. Para terminar, agradezco sinceramente también las facilidades dadas y las orientaciones recibidas en el Archivo Histó-
} 


\section{Aviadores en el desierto...}

rico del Ejército del Aire, especialmente las de sus bibliotecarias, $D^{a}$ Carmen Urquiaga, $\mathrm{D}^{\mathrm{a}}$ Paloma Bengoechea y el resto del personal auxiliar.

1 El relato de su experiencia y viaje lo publicó R. Martínez Esteve en un libro que alcanzó una gran difusión: MARTÍNEZ ESTEVE, R. (1926). Una aventura en el desierto. Editorial Espasa Calpe, Madrid. Aunque lógicamente he manejado la edición original -de la que proceden parte de las ilustraciones del artículo-, las referencias textuales y la paginación se refieren a la edición completa e integrada de los libros y los grandes viajes de la aviación española emprendidos en 1926, excelentemente documentada con fotografias e ilustraciones de la época, que gentilmente me facilitó el Excmo. Sr. General Don Luis Castañón Albo, Director del Museo del Aire. Así pues, las notas se referirán a esta edición MARTÍNEZ EsTEVE, R. (2001): Una aventura en el desierto, en SÁNCHEZ MÉNDEZ, J. (coord.) (2001): Relatos para la historia. LXXV aniversario de los tres primeros grandes vuelos de la aviación militar española. Fundación AENA / Servicio Histórico y Cultural del Ejército del Aire, Madrid, pp. 207-240. Para la referencia citada entre texto véase p. 227.

2 Sobre la vida de Rafael Martínez Esteve véanse FERNÁNDEZ DE LATORRE, R. (2001): «En el LXXV Aniversario del Vuelo Madrid-Manila. ¿Qué fue de Rafael Martínez Esteve?. La última aventura del "héroe del desierto» y la de su familia», Aeroplano 19, pp. 21. 32, y también OLLer GARCíA, J. (2005): «Aviadores para la Historia. Coronel Rafael Martínez Esteve. Biografía resumida, 1894-1965», en la página web de la Fundación Aérea de la Comunidad de Valencia.

${ }^{3}$ Sobre la vida de Ladislaus E. Almásy véase el prólogo de R. Schrott y M. Farin en la edición española de ALMÁsy, L. E. (1999): Nadadores en el desierto. A la búsqueda del oasis de Zarzura. Ediciones Península, Barcelona, pp. 7-18, y el cuadernillo con fotografías de su vida, vuelos y exploraciones que acompaña esta edición.

${ }^{4}$ La fama personal y literaria alcanzada por Antoine de Saint-Exupéry hace que existan diversas biografías y una larga bibliografía. Me remito a la muy sencilla pero ilustrativa de DES VALLIÈRES, N. (1998): Saint-Exupéry. L'archange et l'écrivain. Gallimard, Paris. Su amplia obra literaria ha sido traducida a todas las lenguas.

5 GoNZÁlez-BeTES, A. (1990): “Cabo Juby. Su historia aeronáutica», Aeroplano 8, pp. 82-89. Sobre el vuelo de Martínez Esteve, p. 86. Respecto a la presencia allí de A. de Saint-Exupéry, pp. 87-88.

6 Me remito a R. Schrott y M. Farin en su prólogo a la edición española de ALMÁSY, L. E. (1999): op. cit., pp. 7-18.

7 La semblanza biográfica de Antoine de Saint-Exupéry está basada, fundamentalmente, en la biografía citada a cargo de DES VALLIÈRES, N. (1998): op cit. Como no quiero más que una aproximación a su vida, creo que se excusa la reiteración de citas.

8 En abril y mayo estaba realizando operaciones de bombardeo y reconocimiento en la región de Yebala, y el 17 de septiembre llevó a cabo un aterrizaje forzoso que le ocasionó heridas leves. Véase OLLER GaRCíA, J. (2005): op. cit.

${ }^{9}$ De su presencia junto al fuerte español y su persona, de su cordialidad con Hidalgo de Cisneros y los otros pilotos españoles véase, GonZÁLEZ-BETES, A. (1990): op. cit., pp. 87-88.

10 Des VallièreS, N. (1998): op cit., p. 45.

11 DES VALLIĖRES, N. (1998): op cit., p. 94.

12 Para la biografía de Rafael Martínez Esteve he recurrido principalmente a las informaciones facilitadas por las personas que se indican en los agradecimientos, a los trabajos de FERNÁNDEZ DE LATORRE, R. (2001): op. cit., OlLER GARCíA, J. (2005):, op. cit. y naturalmente a la documentación del Archivo Histórico del Ejército del Aire, Expediente Personal 71510. 
${ }^{13}$ La línea estaba ya abierta por los franceses en 1923, entre los que participaba el oficial español Roig. La expedición española le fue propuesta por el coronel Bens al director de la Aeronáutica Militar, dada la preponderancia que los franceses estaban tomando en el área. Sobre el vuelo del hidro y los Breguet véase GoNZÁlEZ-BETES, A. (1990): op. cit., pp. 86-87. Y sobre la presencia de A. de Saint-Exupéry, pp.87-88.

14 Aunque impuesto por las circunstancias, lo cierto es que fue causa de grandes pérdidas humanas y de material. Sobre este tipo de vuelo véase SALAS, R. (1983): «Los primeros tiempos de nuestra aviación", Aeroplano, 1, pp. 14-33. Vid. p. 25.

15 Sobre el capitán Joaquín Boy Fontelles véase Flores Alonso, A. (1989): «Cartas marruecas. Vida y tragedia del capitán Boy Fontelles», Aeroplano, 6, pp. 30-40. Respecto al asedio de la posición de Tifarauin, véase HerRera ALONSO, E. (1987): «La aviación en el socorro a Tifarauin», Aeroplano, 5, pp. 22-30.

16 OLLER García, J. (2005): op. cit.

17 SALAS, R. (1093): op. cit., pp. 25-29.

18 Véase SALAS, R. (1093): op. cit., pp. 27-28, y naturalmente la publicación conjunta de los tres vuelos en el libro editado con ocasión del LXXV aniversario ya antes citado: SÁNCHEZ MÉNDEZ, J. (coord.) (2001): Relatos para la historia. LXXV aniversario de los tres primeros grandes vuelos de la aviación militar española. Fundación AENA / Servicio Histórico y Cultural del Ejército del Aire, Madrid.

19 El texto se publica en el libro de Gallarza y Loriga El vuelo Madrid Manila, recogido en SÁNCHEZ MÉNDEZ, J. (coord.) (2001): op. cit., pp. 128-132.

20 SALAS, R. (1983): op. cit., p. 28.

${ }^{21}$ Sigo la edición de su libro y la paginación correspondiente en SÁNCHEZ MÉNDEZ, J. (coord.) (2001): op. cit., pp. 207-240.

22 En el hangar $n^{\circ} 1$, la maqueta MAA 399, modelo del avión $n^{\circ} 4$ llevado por Rafael Martínez Esteve, bautizado Elcano. Para más detalles véase el volumen Maquetas del Museo del Aire. Serie $n^{0} 2$ de la Colección: Aeronaves de España. La ficha n 10 está dedicada a la de este aparato, realizada por Félix Luengo y por encargo del Museo en 1983, para la exposición conmemorativa del aniversario del vuelo. 